\title{
Posturally induced vasoconstriction in diabetes mellitus
}

\author{
A C Shore, K J Price, D D Sandeman, J H Tripp, J E Tooke
}

\begin{abstract}
In healthy subjects, standing elicits a reduction in blood flow to the skin of the foot. In adults with insulin dependent diabetes this posturally induced response is deficient, resulting in capillary hypertension when the foot is in the dependent position (that is, below heart level). Such functional abnormalities of the microcirculation in diabetes may precede any evidence of clinically detectable microangiopathy. This study investigates the posturally induced change in blood flow to the skin of the foot in prepubertal and postpubertal patients with insulin dependent diabetes. Laser Doppler fluximetry was used to assess the postural change in blood flow at the pulp of the great toe. Postural vasoconstriction (dependent flux value/supine flux value $\times 100$ ) was greater after puberty in normal subjects (median (range) 60.4 (7.0-164.9)\% prepubertal $v$ $20.5(5 \cdot 9-101 \cdot 0) \%$ postpubertal). Prepubertal children with diabetes did not differ from their healthy peers $(69.8$ $(7 \cdot 2-192 \cdot 7) \%$ with diabetes $v 60 \cdot 4(7 \cdot 0-$ $164.9) \%$ controls); however postpubertal children with diabetes had a significantly impaired postural vasoconstriction $(40 \cdot 6$ $(7 \cdot 9-140 \cdot 2) \%$ with diabetes $v \quad 20.5$ $(5 \cdot 9-101 \cdot 7) \%$ controls).

Abnormalities in the normal reduction of blood flow on standing occurred in young postpubertal children with diabetes, most of whom were free of complications.
\end{abstract}

(Arch Dis Child 1994; 70: 22-26)

The occurrence of complications in diabetes is greater after puberty than before, even in subjects matched for duration of diabetes and glycaemic control. ${ }^{1-3}$ However, functional abnormalities of the microcirculation may precede the development of such clinically detectable complications; abnormalities of the microcirculatory response of the skin of the foot to local heating have been shown in young patients with insulin dependent diabetes without complications, and such abnormalities even occur in prepubertal children. ${ }^{4}$

In healthy subjects, a change in posture from lying to standing is accompanied by an increase in the precapillary resistance in the skin of the foot; the increase in capillary pressure on standing is therefore less than would be expected from the posturally induced increase in hydrostatic pressure, ${ }^{5}$ and capillary blood flow in the skin is reduced. ${ }^{6}$ The posturally induced vasoconstriction appears to be mainly caused by a local neurogenic process, ${ }^{78}$ with smaller contributions from local myogenic and central neurogenic components. ${ }^{9}$ Modulation of the response by changes in sex hormones is suggested by observations that postural vasoconstriction is impaired during the luteal phase of the menstrual cycle, and in women taking combined oral contraceptive steroids. ${ }^{10}$ Although the exact mechanism of this impairment has not been deduced, steroid hormones, including oestrogen and progesterone, are known to influence the vascular response to vasoactive agonists. ${ }^{11}$ Whether postural vasoconstriction is influenced by the hormonal changes which accompany puberty is unknown.

Abnormalities in the skin blood flow response to changes in posture have been found in adult patients with insulin dependent diabetes. ${ }^{12}$ It has been argued that a disturbance of this response and the resultant capillary hypertension on standing may lead to damage of the microcirculation, and may also explain the greater than normal increase

Table 1 Clinical details of the patients and controls. Values are median (range) or number of subjects

Diabetes Research
Laboratories,
Postgraduate Medical
School, University of
Exeter
A C Shore
K J Price
D D Sandeman
J H Tripp
J E Tooke
Correspondence to:
Dr A C Shore, Diabetes
Research Laboratories, Noy
Scott House, Haldon View
Terrace, Exeter EX2 5DW.
Accepted 14 September
1993

\begin{tabular}{|c|c|c|c|c|}
\hline & \multicolumn{2}{|c|}{ Children with diabetes } & \multicolumn{2}{|l|}{ Controls } \\
\hline & $\begin{array}{l}\text { Prepubertal } \\
(n=23)\end{array}$ & $\begin{array}{l}\text { Postpubertal } \\
(n=31)\end{array}$ & $\begin{array}{l}\text { Prepubertal } \\
(n=27)\end{array}$ & $\begin{array}{l}\text { Postpubertal } \\
(n=22)\end{array}$ \\
\hline $\begin{array}{l}\text { Age (years) } \\
\text { Vibration perception threshold }(\mathrm{V}) \\
\text { Mean blood pressure (mm } \mathrm{Hg}) \\
\text { Duration of diabetes (years) } \\
\text { Insulin }(\mathrm{U} / \mathrm{kg}) \\
\mathrm{HbA}_{1}(\%)^{\star} \\
\text { No with albumin creatinine ratio } \\
>1.5 \mathrm{mg} / \mathrm{mmol} \\
\text { No with albumin excretion rate } \\
>20 \mu \mathrm{g} / \mathrm{min} \\
\text { No with retinopathy }\end{array}$ & $\begin{array}{l}10 \cdot 0(5 \cdot 5-12 \cdot 2) \\
4 \cdot 6(3 \cdot 0-9 \cdot 5) \\
81 \cdot 0(63 \cdot 2-93 \cdot 7) \\
2 \cdot 7(0 \cdot 01-9 \cdot 8) \\
0 \cdot 8(0 \cdot 2-1 \cdot 3) \\
11 \cdot 8(8 \cdot 4-14 \cdot 9) \\
3 \\
\\
0 \\
0\end{array}$ & $\begin{array}{l}15 \cdot 9(13 \cdot 6-19 \cdot 0) \\
5 \cdot 8(1 \cdot 4-12 \cdot 5)^{f} \\
83 \cdot 5(73 \cdot 3-94 \cdot 6) \\
6 \cdot 2(0 \cdot 4-13 \cdot 4)^{5} \\
0 \cdot 9(0 \cdot 3-1 \cdot 3)^{f} \\
11 \cdot 5(6 \cdot 7-16 \cdot 2) \\
2 \\
1 \\
2\end{array}$ & $\begin{array}{c}9 \cdot 3(6 \cdot 3-12 \cdot 0) \\
4 \cdot 3(3 \cdot 0-11 \cdot 7) \\
76 \cdot 2(65 \cdot 8-85 \cdot 3)\end{array}$ & $\begin{array}{r}15 \cdot 7(11 \cdot 6-18 \cdot 5) \\
5 \cdot 9(3 \cdot 4-16 \cdot 0)^{\star \star} \\
77 \cdot 2(68 \cdot 7-92 \cdot 5)\end{array}$ \\
\hline
\end{tabular}

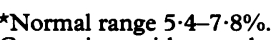

Comparison with prepubertal children with diabetes: ${ }^{t} p=<0.03 ;{ }^{\prime} p=<0.01 ; \mathrm{S}=<0.005 ; \mathrm{p}=<0.02$

Comparison with postpubertal children with diabetes: $\mathrm{p}=<0.001$. Comparison with prepubertal controls: ${ }^{\star \star} p=<0 \cdot 005$ 
in capillary basement membrane thickness observed in tissues sampled from the distal lower limb in patients with diabetes. ${ }^{13} 14$

The aim of the present study was therefore to assess whether postural vasoconstriction was altered by puberty in healthy subjects and furthermore to assess whether this response was preserved in prepubertal and postpubertal children with insulin dependent diabetes.

\section{Patients and methods}

Table 1 gives details of the patient and control groups. Each child with diabetes was screened for clinical neuropathy and microangiopathy. The vibration perception threshold was determined as the mean of six readings on the pulp of the great toes using a Biothesiometer (Bio Medical Instruments, Newbury, OH, USA). No significant difference was noted in the children with diabetes compared with controls.

A timed overnight urine collection was screened for microalbuminuria in 50 of the 54 children with diabetes; the remaining patients refused to provide a urine sample. Albumin was measured by an immunoturbidometric method and the albumin creatinine concentration ratio (ACR) was calculated (urinary albumin (mg/l)/urinary creatinine ( $\mathrm{mmol} / \mathrm{l})$ ). If the screening ACR was greater than 1.5 $\mathrm{mg} / \mathrm{mmol}$, three timed overnight urine samples were obtained to determine if the child had consistently increased albumin excretion (normal range of non-diabetic schoolchildren $0 \cdot 15-1.64 \mathrm{mg} / \mathrm{mmol})$. Twelve of the children with diabetes had a screening ACR greater than $1.5 \mathrm{mg} / \mathrm{mmol}$; five of these had an ACR persistently greater than this value; however, only one of these five patients had an albumin excretion rate greater than $15 \mu \mathrm{g} / \mathrm{min}$ in more than one overnight urine collection. This patient's albumin excretion rates were $42 \cdot 7$, 115.4 , and $114.3 \mu \mathrm{g} / \mathrm{min}$ and he would therefore be categorised as microalbuminuric using the criteria established for the adult diabetic population. ${ }^{15}$

Retinal examination was performed on each of the children with diabetes by an ophthalmologist specialising in diabetic eye disease or by a diabetologist. Eighteen of the children also had retinal photographs taken using a non-midriatic camera (Canon CR3-45 mm, Canon, Tokyo, Japan). Only two adolescents with diabetes showed any retinal abnormalities.

Each child was assessed for pubertal stage using the criteria of Tanner; only those subjects who were prepubertal $\left(P_{1} G_{1}(n=50)\right.$ or postpubertal $\left(P_{5} G_{5}\right)(n=53)$ are included in this analysis. In the diabetic group a blood sample for glycated haemoglobin $\left(\mathrm{HbA}_{1}\right.$ by column chromatography; Biorad, Richmond, CA, USA) was obtained at the time of the study as part of the child's routine medical care (normal range $5 \cdot 4-7 \cdot 8 \%$ ). In all subjects blood pressure was measured by the oscillometric technique (Dinamap, Critikon, Tampa, FL, USA) six times during the study (two periods of three measurements recorded at one minute intervals). The mean of the final two blood pressure measurements after one hour supine was taken as the subject's true blood pressure.

The study was approved by the local ethical committee and consent was obtained from each child and guardian after the nature of the procedure had been explained.

The studies were conducted after a 30 minute period of acclimatisation in an environmentally controlled room $\left(22 \cdot 0 \pm 0 \cdot 4^{\circ} \mathrm{C}\right)$. The red cell flux at the pulp of the great toe was measured by laser Doppler fluximetry (Periflux pf $2 \mathrm{~b}$, Perimed, Stockholm, Sweden), initially with the subject supine and the foot at heart level and then for five minutes with the foot passively lowered to $40 \mathrm{~cm}$ below the heart and the knee bent. The change of blood flow with posture in the children followed a similar time course to that shown previously in adults - that is, a flat plateau of blood flow was usually reached during the first two minutes of dependency. The postural vasoconstriction (PV) response was calculated as a percentage from the mean flux measured over the fourth and fifth minute with the foot in the dependent position (DF) divided by the mean flux obtained in the final two minutes with the foot at heart level (HF).

$$
\mathrm{PV}=\frac{\mathrm{DF}}{\mathrm{HF}} \times 100
$$

Biological zero - that is, the laser Doppler signal remaining when an ankle cuff was inflated to cause arterial occlusion - was subtracted from the two flux values before the postural vasoconstriction was calculated. The temperature of the skin of the foot was continuously recorded using an adherent thermocouple (Comark Electronic, Littlehampton, Sussex) at the pulp of the great toe.

The reproducibility of the method has previously been assessed by studying six men on three separate occasions. Change in posture reduced skin blood flow to $18.3(4 \cdot 5), 18.6$ (3.1), and $19 \cdot 2(4 \cdot 3) \%$ (mean (SD)) of the supine value respectively. In three postpubertal subjects measured on two occasions more than one year apart, the blood flow when the foot was in the dependent position as a percentage of the basal flow was 12.9 and $12 \cdot 0 \%$ (subject 1), $10 \cdot 7$ and $3 \cdot 4 \%$ (subject 2 ), and 5.9 and $11.3 \%$ (subject 3 ). In three young prepubertal children measured on two occasions more than one year apart (weight change $<3.0 \mathrm{~kg}$ ), blood flow in the dependent position as a percentage of basal flow was 40.0 and $43.3 \%$ (subject 1 ), 51.7 and $51.3 \%$ (subject 2), and 30.5 and $25.9 \%$ (subject 3).

\section{STATISTICAL METHODS}

The data are presented as median (range). Several of the variables showed significant skewness or kurtosis, or both. Comparisons between groups was by the Kruskal-Wallis analysis of variance followed, where significant, by Mann-Whitney U tests. Associations between variables were assessed by Spearman's rank correlation coefficient. 
Table 2 Data for the red cell flux at the pulp of the great toe with the foot at heart level, the toe pulp flux with the foot dependent, skin temperature, and postural vasconstriction in prepubertal and postpubertal healthy children and children with diabetes

\begin{tabular}{|c|c|c|c|c|}
\hline & \multicolumn{2}{|c|}{ Children with diabetes } & \multicolumn{2}{|l|}{ Controls } \\
\hline & Prepubertal & Postpubertal & Prepubertal & Postpubertal \\
\hline $\begin{array}{l}\text { Red cell flux, foot at heart level (V) } \\
\text { Red cell flux, foot down (V) } \\
\text { Toe skin temperature }\left({ }^{\circ} \mathrm{C}\right) \\
\text { Postural vasoconstriction }(\%)\end{array}$ & $\begin{array}{c}0.73(0 \cdot 1-3 \cdot 0) \\
0 \cdot 73(0 \cdot 01-3 \cdot 1) \\
28 \cdot 4(22 \cdot 2-33 \cdot 9) \\
69 \cdot 8(7 \cdot 2-192 \cdot 7)\end{array}$ & $\begin{array}{l}0 \cdot 12(0 \cdot 05-2 \cdot 74)^{\ddagger} \\
0 \cdot 05(0 \cdot 01-3 \cdot 8)^{\ddagger} \\
24 \cdot 4(21 \cdot 0-33 \cdot 6)^{\dagger} \\
40 \cdot 6(7 \cdot 9-140 \cdot 2)\end{array}$ & $\begin{array}{c}0.60(0.04-3.4) \\
0.43(0.03-2 \cdot 1) \\
26.5(21.5-33.9) \\
60.4(7.0-164.9)\end{array}$ & $\begin{array}{c}0 \cdot 12(0.02-2 \cdot 12)^{\|} \\
0 \cdot 03(0.01-0 \cdot 68)^{\star \ddagger} \\
23 \cdot 0(20 \cdot 9-33 \cdot 3)^{4} \\
20 \cdot 5(5 \cdot 9-101 \cdot 7)^{\star \star \S}\end{array}$ \\
\hline
\end{tabular}

Comparison between diabetics and controls: ${ }^{\star} \mathrm{p}<0.05 ;{ }^{\star \star} \mathrm{p}<0.007$. Comparison within groups $v$ prepubertal peers: ${ }^{\dagger} \mathrm{p}<0.01$; ${ }_{\mathrm{p}}<0.001 ;{ }^{\mathrm{S}} \mathrm{p}=0.0001 ;{ }^{\mathrm{p}}<0.005 ;{ }_{\mathrm{p}}=0.0005$.

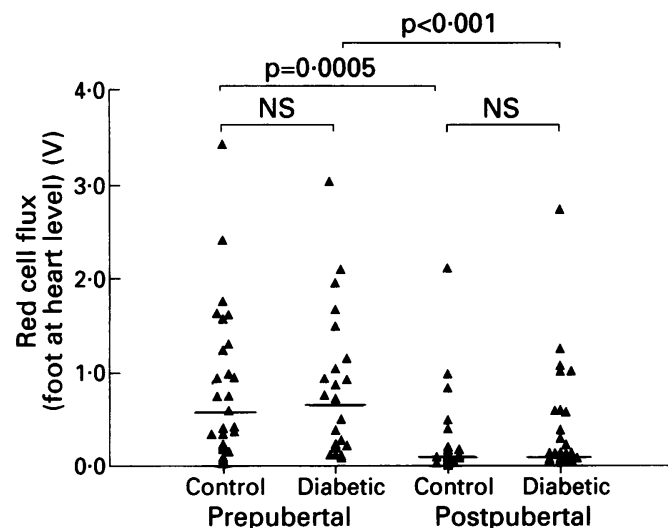

Figure 1 Red cell flux measured at the pulp of the great toe in prepubertal and postpubertal healthy children and children with diabetes mellitus. Subjects were lying supine with the foot at heart level. The median value of each group is marked.

\section{Results}

With the subjects supine, the red cell flux and skin temperature at the great toe did not differ significantly in prepubertal healthy children and in children with diabetes.

In the two groups, puberty was associated with a marked reduction in resting red cell flux (fig $1, \mathrm{p}<0.001$ prepubertal $v$ postpubertal children with diabetes; $p=0.0005$ prepubertal $v$ postpubertal controls) and skin temperature $(\mathrm{p}<0.01$ prepubertal $v$ postpubertal children with diabetes; $p<0.005$ prepubertal $v$ postpubertal controls). There was no significant difference in these two parameters in the postpubertal children with diabetes compared with the controls.

In prepubertal children with diabetes and prepubertal control children, the posturally induced vasoconstriction was poor; indeed, in

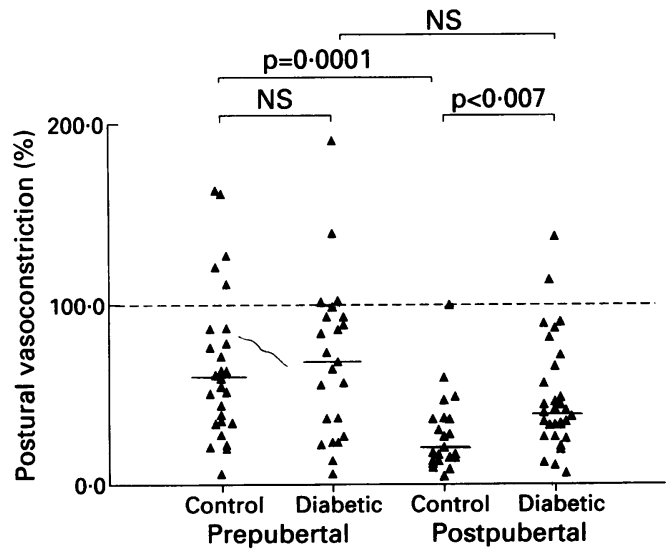

Figure 2 Postural vasoconstriction of the skin of the pulp of the great toe in children with diabetes and healthy controls. The median of each group is marked. five control subjects and five children with diabetes lowering the foot below the heart was accompanied by no change or an increase in blood flow instead of a reduction. Puberty was associated with a marked improvement of the postural vasoconstrictor response in healthy adolescents $(60.4(7 \cdot 0-164.9) \%$ prepubertal $v$ $20.5(5 \cdot 9-101 \cdot 7) \%$ postpubertal; $\mathrm{p}=0.0001)$. In the adolescents with diabetes, however, the improvement in the postural vasoconstrictor response associated with puberty was less marked $(69.8(7 \cdot 2-192 \cdot 7) \%$ prepubertal $v$ $40.6(7 \cdot 9-140 \cdot 2) \%$ postpubertal; $\mathrm{p}=0.083)$ and postural vasoconstriction was thus significantly impaired compared with their healthy peers $(p<0.007$; fig 2$)$. In the two postpubertal groups about half of the girls (7/15 controls; $11 / 19$ children with diabetes) were in the follicular phase of their menstrual cycle, and there was no significant difference in the mean day of the menstrual cycle in the two groups $(p=0 \cdot 9)$.

In the group of prepubertal children with diabetes, the postural vasoconstriction response was related to $\mathrm{HbA}_{1}\left(r_{\mathrm{s}}=0.51 ; \mathrm{p}=0.018\right)$, skin temperature $\left(r_{\mathrm{s}}=0.63 ; \mathrm{p}=0.001\right)$, and systolic and diastolic blood pressure $\left(r_{\mathrm{s}}=0.50, \mathrm{p}=0.02\right.$, systolic blood pressure; $r_{\mathrm{s}}=0.45, \mathrm{p}<0.05$ diastolic blood pressure; there was no association with duration of diabetes $\left(r_{\mathrm{s}}=0.089\right)$ or insulin $\left(r_{\mathrm{s}}=-0 \cdot 064\right)$. These findings differ from those in prepubertal healthy children in whom postural vasoconstriction does not correlate with skin temperature $\left(r_{\mathrm{s}}=0.015\right)$, or systolic or diastolic blood pressure $\left(r_{\mathrm{s}}=-0.3575, \mathrm{p}=0.07\right.$ systolic blood pressure; $r_{\mathrm{s}}=0 \cdot 14$ diastolic blood pressure.

In the postpubertal subjects with diabetes there was a weak association of postural vasoconstriction with skin temperature $\left(r_{\mathrm{s}}=0.35\right.$; $\mathrm{p}=0.052$ ), but there were no other significant associations $r_{\mathrm{s}}=-0.01 \mathrm{HbA}_{1} ; r_{\mathrm{s}}=0.12$ systolic blood pressure; $r_{\mathrm{s}}=0.27$ diastolic blood pressure; $r_{\mathrm{s}}=0.07$ duration of diabetes; $r_{\mathrm{s}}=0.08$ insulin; $r_{\mathrm{s}}=0.033$ day of menstrual cycle). Postural vasoconstriction showed no significant association in the healthy postpubertal group $\left(r_{\mathrm{s}}=-0.02\right.$ skin temperature; $r_{\mathrm{s}}=-0.016$ systolic blood pressure; $r_{\mathrm{s}}=-0.015$ diastolic blood pressure; $r_{\mathrm{s}}=-0.35, \mathrm{p}=0.2$ day of menstrual cycle).

\section{Discussion}

This study shows that, in healthy subjects, the vasoconstriction of the skin of the great toe, induced by placing the foot below heart level, is improved with passage through puberty. In healthy adolescents, as in healthy adults, the 
blood flow with the foot in the dependent position was reduced to about one quarter of the supine value. ${ }^{9}$ The growth spurt accompanying puberty would increase the venous pressure of the foot during standing and thus the hydrostatic stress on the microcirculation of the foot. Improvement in this protective postural vasoconstrictor mechanism at puberty would serve to minimise the increase in foot skin capillary pressure during standing and hence limit the formation of oedema. ${ }^{5}$

Whether the change in the sensitivity of the postural vasoconstrictor response to a standard change in pressure induced by puberty is due to a change in the detection of, or an enhanced response to, the stimuli, cannot be deduced from this study. The hormonal changes which accompany puberty may be associated with significant alterations in the vascular reactivity to vasoactive agents and thus the response of the venoarteriolar reflex. ${ }^{1617}$

Indirect heating of the body trunk in adults results in an impairment of the postural vasoconstrictor response at the pulp of the great toe. ${ }^{18}$ Under these circumstances the thermoregulatory control of the body overrides the hydrostatic control mechanisms. The initially high basal metabolic rate, mouth temperature and, in our study, skin temperature in prepubertal children decreases with the passage through puberty. ${ }^{19} 20$ The improvement in the postural vasoconstrictor response maybe related to this reduction in thermoregulatory load.

This study also shows that the postural vasoconstrictor response is abnormal in adolescents with diabetes. Prepubertal children with diabetes showed a poor postural vasoconstrictor response, which did not differ significantly from that of their healthy peers. Interestingly, the postural vasoconstrictor response was closely associated with skin temperature in prepubertal children with diabetes but not in controls, despite equivalent temperatures in the two groups. This may represent an increase in sensitivity in the thermoregulatory control of the blood vessels in prepubertal children with diabetes. Postural vasoconstriction was also associated with $\mathrm{HbA}_{1}$ and blood pressure in prepubertal patients with diabetes, whereas, in contrast, blood pressure was not significantly related to postural vasoconstriction in prepubertal or postpubertal control subjects or postpubertal children with diabetes. These findings raise the possibility that subtle abnormalities of the postural vasoconstrictor response may be occurring even in young patients with diabetes of short disease duration.

The improvement in postural vasoconstriction which normally accompanies the passage through puberty was less marked in the diabetic group, with the result that the response was significantly impaired in adolescents with diabetes compared with controls. This abnormality in microvascular control occurred before the emergence of clinically detectable microvascular complications in most patients. The cause of the abnormal postural vasoconstriction is uncertain. It is unlikely to be related to glycaemic control or duration of diabetes as no significant associations were found between postural vasoconstriction and glycaemic control in the postpubertal group, or between duration of diabetes and postural vasoconstriction in either diabetic group.

Possible explanations for the deficient postural vasoconstriction in adolescents with diabetes include an abnormal response of the blood vessels to either the increase in intravascular pressure or the posturally induced increase in sympathetic discharge; such altered responsiveness may be due to abnormalities of the endothelial or vascular smooth muscle cell function, several of which have been described in experimental and human diabetes ${ }^{21-31}$; however, vascular abnormalities in uncomplicated diabetes are less well documented. ${ }^{32} 33$ Thickening of the capillary basement membrane occurs in adolescents with diabetes, particularly those with poor control; this may alter the response to stimuli although the vasodilatory capacity of the skin appears to be more affected than vasoconstriction. ${ }^{34-35}$ Subtle abnormalities in nervous function occur early in diabetes ${ }^{36}$ and may also influence the postural vasoconstrictor response.

In patients with diabetes with severe hyperglycaemia and ketoacidosis, the resting metabolic rate is increased ${ }^{37}$; improvement of glycaemic control returns the resting metabolic rate to normal levels. ${ }^{37} 38$ Food or stress induced thermogenesis is, however, increased in patients with diabetes ${ }^{38}$ and, together with the metabolic rate changes which accompany normal puberty, may influence the postural vasoconstrictor response in diabetes. None of the subjects in our study had hyperglycaemia or ketoacidosis. The basal metabolic rate was not measured in this study; however, skin temperatures did not differ significantly in the two postpubertal groups. If thermogenesis was increased in our postpubertal diabetic group, we might expect an impaired postural vasoconstriction as an experimental increase in body temperature, by heating of the body trunk, has previously been shown to cause impairment of postural vasoconstriction measured at the pulp of the great toe. ${ }^{18}$

In conclusion, in children with diabetes passage through puberty does not appear to be associated with the acquisition of an enhanced adult postural vasoconstrictor response as observed in healthy children. The likely result of this abnormality is that the microcirculation of the foot will be exposed to greater hydrostatic stress. Similar haemodynamic abnormalities emerging in other microcirculatory beds at puberty may explain, at least in part, the accelerated rate of accrual of diabetic microangiopathy at this stage of development.

This work was supported by the Wellcome Trust, the Devon Northcott Foundation, and the British Diabetic Association.

1 Rogers DG, White NH, Shalwitz RA, Palmberg P, Smith ME, Santiago JV. The effect of puberty on the development of early diabetic microvascular disease in insulindependent diabetics. Diabetes Res Clin Pract 1987; 3: 39-44.

2 Dahquist G, Rudberg S. The prevalence of microalbuminuria in diabetic children and adolescents and its relation to puberty. Acta Paediatr Scand 1987; 76: 795-800.

3 Klein R, Klein BEK, Moss SE, Davis MD, DeMets DL. Retinopathy in young-onset diabetic patients. Diabetes Care 1985; 8: 311-5. 
4 Shore AC, Price KJ, Sandeman DD, Green EM, Tripp JH Tooke JE. Impaired microvascular hyperaemic response in children with diabetes mellitus. Diabetic Med 1991; 8 619-23.

5 Levick JR, Michel CC. The effects of position and skin temperature on capillary pressure in the fingers and toes. f Physiol 1978; 274: 97-109.

6 Flynn MD, Hassan AAK, Tooke JE. Effect of postural change and thermoregulatory stress on the capillary microcirculation of the human toe. Clin Sci 1989; 76: 231-6.

7 Henriksen $O$. Local nervous mechanism in regulation of blood flow in human subcutaneous tissue. Acta Physio

8 Henriksen O, Sejrsen P. Local reflex in microcirculation in human cutaneous tissue. Acta Physiol Scand 1976; 98: 227-31

9 Hassan AAK, Tooke JE. The mechanism of the postural vasoconstrictor response in the human foot. Clin Sci 1988; 75: 379-87.

10 Hassan AAK, Carter G, Tooke JE. Postural vasoconstriction in women during the normal menstrual cycle. Clin Sci 1990; 78: 39-47.

11 Altura BM, Altura BT. Influence of sex hormones, oral contraceptives and pregnancy on vascular muscle and its reactivity. In: Carrier O, Shibata S, eds. Factors influencing vascular reactivity. Tokyo, New York: Igaku-Shoin, 1977

12 Rayman G, Hassan AAK, Tooke JE. Blood flow in the skin of the foot related to posture in diabetes mellitus. $B M \mathcal{F}$ 1986; 292: 87-90.

13 Tooke JE. Microvascular haemodynamics in diabetes mellitus. Clin Sci 1986; 70: 119-25.

14 Vracko R. Skeletal muscle capillaries in diabetics. Circulation 1970; 41: 271-83.

15 Viberti GC, Jarrett RJ, Mahmud U, Hill RD, Argyropoulos A, Keen $\mathrm{H}$. Microalbuminuria as a predictor of clinical nephropathy in insulin-dependent diabetes mellitus. Lancet 1982; i: 1430-2.

16 Altura BM. Sex and oestrogens and responsiveness of terminal arterioles to neurohypophyseal hormones and catecholamines. If Pharmacol Exp Ther 1975; 193: 403-12

17 Dhall U, Cowen T, Haven AJ, Burnstock G. Effect of oestrogen and progestrogen on noradrenergic nerves and on nerves showing serotinin like immunoreactivity in the basilar artery of the robbit. Brain Res 1988, 442: 335 .

18 Hassan AAK, Rayman G, Tooke JE. Effect of indirect heating on the postural control of skin blood flow in the human foot. Clin Sci 1986; 709: 577-82.

19 Shock NW. Some physiological responses of adolescence Texas Reports on Biology and Medicine 1946; 4:289-310.

20 Iliff A, Lee VA. Pulse rate, respiratory rate and body temperature of children between 2 months and eighteen years of age. Child Dev 1952; 23: 237-45.

21 Durante W, Sen AK, Sunahara FA. Impairment of endothelium-dependent relaxation in aorta from spontaneously diabetic rats. Br $\mathcal{F}$ Pharmacol 1988; 94: 463-8.

22 Kamata $\mathrm{K}$, Miyata N, Kasuya Y. Impairment of endothelium-dependent relaxation and changes in levels of cGMP in aorta from streptozotocin-induced diabetic rats. Br f Pharmacol 1989; 97: 614-8.
23 Koltai MZ, Rosen P, Ballagi-Pordany G, Hadhazy P, Pogatsa G. Increased vasoconstrictor response to noradrenaline in femoral vascular bed of diabetic dogs. Is thomboxane $\mathrm{A}_{2}$ involved? Cardiovasc Res 1990; 24: 707-10.

24 MacLeod $\mathrm{KM}, \mathrm{McNeill} \mathrm{JH}$. The influence of chronic experimental diabetes on contractile responses of rat
isolated blood vessels. Can $\mathcal{F}$ Physiol $1985 ; 63: 52-7$.

25 Hill MA, Meininger GA, Larkins RG. Alterations in microvascular reactivity in experimental diabetes mellitus: contributions of the endothelium. In: Molinatti GM, Bar RS, Belfiore F, Porta M, eds. Endothelial cell function in diabetic microangiopathy: problems in methodology and clinical aspects. Front diabetes. Vol 9. Basle: Karger, 1990: 118-26.

26 Hill MA, Meininger GA, Granger HJ. Altered skeleta muscle microvascular haemodynamics after one week of streptozotocin-induced diabetes. Microcirc Endothelium Lymphatics 1985; 2: 687-704.

27 Morff RJ. Microvascular reactivity to norepinephrine at different arteriolar levels and durations of streptozotocinferent arteriolar levels and durations of strept
induced diabetes. Diabetes 1990; 39: 354-60.

28 Christlieb AR, Janka HU, Kraus B, et al. Vascular reactivity to angiotensin II and noradrenaline in diabetic subjects. Diabetes 1976; 25: 268-74.

29 Westerman RA, Widdop RE, Hogan C, Zimmet P. Noninvasive tests of neurovascular function: reduced response in diabetes mellitus. Neurosci Lett 1987; 81: 177-82.

30 Parkhouse N, Le Quesne PM. Impaired neurogenic yascular response in patients with diabetes and neuropathic foot lesions. N Engl f Med 1988; 318: 1306-9.

31 Aronin N, Leeman SE, Clements RS. Diminished flare response in neuropathic diabetic patients. Diabetes 1987 36: 1139 .

32 Boolell $\mathrm{M}$, Tooke JE. The skin hyperaemic response to loca injection of substance $P$ and capsaicin in diabetes mellitus. Diabetic Med 1990; 7: 898-901.

33 Calver A, Collier J, Vallance P. Inhibition and stimulation of nitric oxide synthesis in the human forearm arterial bed of patients with insulin-dependent diabetes. $f$ Clin Invest 1993; 90: 2548-54

34 Rogers DG, White NH, Santiago JV, et al. Glycaemic control and bone age are independently associated with muscle capillary basement membrane width in diabetic children after puberty. Diabetes Care 1986; 9: 453-9.

35 Kastrup J, Norgaard $T$, Parving $H-H$, Arteriolar hyalinosis does not interfere with the local veno-arteriolar reflex regulation of subcutaneous blood veno-arteriolar reflex regulation of subcutaneous blood flow in insulin-dependent diat

36 Eng GD, Hung W, August GP, Smokvina MD. Nerve conduction velocity determinations in juvenile diabetes: continuing study of 190 patients. Arch Phys Med Rehabil 1976; 57: 1-5.

37 Nair KS, Halliday D, Garrow JS. Increased energy expenditure in poorly controlled type I insulin dependent diabetes mellitus. Diabetologia 1984; 27: 13-6.

38 Muller MJ, von zur Muhlen A, Lautz HU, Schmidt FW, Daiber MD, Hurter P. Energy expenditure in children with type I diabetes: evidence for increased children with type I diabetes: evidence
genesis. BMF 1989; 299: 487-90. 